\title{
The Impact of Cross-Industry Pollution, Consumer Environmental Awareness, and Corporate Social Responsibility on Industrial Environmental Policies
}

\author{
Chu-Chuan Hsu \\ Department of Marketing and Logistics Management, Yu Da University of Science and Technology, Taiwan \\ Email: edison9@ydu.edu.tw
}

How to cite this paper: Hsu, C.-C. (2021). The Impact of Cross-Industry Pollution, Consumer Environmental Awareness, and Corporate Social Responsibility on Industrial Environmental Policies. Modern Economy, 12, 826-848.

https://doi.org/10.4236/me.2021.124041

Received: March 9, 2021

Accepted: April 23, 2021

Published: April 26, 2021

Copyright (c) 2021 by author(s) and Scientific Research Publishing Inc. This work is licensed under the Creative Commons Attribution International License (CC BY 4.0).

http://creativecommons.org/licenses/by/4.0/

\begin{abstract}
In this paper, I established a cross-industry pollution externality design and used the three-stage game analysis framework to discuss the issues linked to firm output, labor union negotiation wages, and the government's optimal environmental tax. We show that with environmentally oriented corporate social responsibility, the government's optimal environmental tax rate and firms' residual pollution abatement level will decrease, which is conducive to environmental protection, and the negotiated wages of all firms will increase. With environmentally oriented corporate social responsibility, the profits and union utility of industry firms will increase, as will the overall consumer surplus and the social welfare level, but there will be no effect on the profit and union utility of firms whose productivity is reduced by pollution.
\end{abstract}

\section{Keywords}

Cross-Industry Pollution, Corporate Social Responsibility, Consumer Environmental Awareness

\section{Introduction}

The impacts of industrial policies on environmental quality have always been the focus of attention of the government and the public. There are several significant problems caused by the greenhouse effect ${ }^{1}$, such as air and water pollution. The use of renewable energy is recognized by global governments and consumers as ${ }^{1}$ Wikipedia, Greenhouse effect. Available online: https://en.wikipedia.org/wiki/Greenhouse_effect (accessed on 18 March 2021). 
the green supply chain in production and the pollution process control of high-tech industries ${ }^{2}$. Green consumer behaviors are common in addressing organic agriculture, environmental plastic reduction, and marine resource issues. People generally agree that environmental governance can improve consumers' awareness of environmental consumption, thereby forming consumers' green brand identity, which has been widely confirmed by academia and practice in green marketing and green consumer behavior. In the empirical article of Laroche et al. (2001), it was revealed that in 1989, about $67 \%$ of American people were willing to spend $5 \%-10 \%$ more for ecologically compatible products, and pay $15 \%-20 \%$ more for green products in 1991 . In this context, producers are focused on corporate social responsibility, while simultaneously increasing their willingness to consume. Profitable thinking can no longer meet the expectations of shareholders and the general public. This is an important issue in the government's environmental regulatory policy. For example, the Taiwanese government encourages higher environmental protection standards and the use of renewable energy, and it provides policy subsidies for buying the "Gogoro" electric scooter ${ }^{3}$ and the fuel motorcycle of Taiwan's seventh-phase emission standard (equal to the Euro 5th emission standard ${ }^{4}$ ). A large number of consumers buy the electric scooter due to both policy subsidies and environmental awareness. Consumers are increasingly willing to pay higher prices for agricultural products because of their organic or environmentally friendly production that is not polluted by pesticides, and industries including Taiwan Semiconductor Manufacturing Company Limited (TSMC) and Google are willing to choose more costly wind and solar power or other green energies for production in Taiwan ${ }^{5}$. These environmentally conscious companies and consumers can achieve a win-win situation for both firms and consumers simultaneously. These behaviors have become an important topic of concern because of today's high environmental awareness.

In the past, Simpson (1995), Katsoulacos and Xepapadeas (1995), Damania (1996), Kato (2006), Lahiri and Ono (2007), Canton, Soubeyran, and Stahn (2008), Lehmann (2010), and Cato (2010) conducted research on environmental policies, focusing mostly on the impact of production costs, the willingness to perform pollution abatement, and the degree of environmental damage of the environmental policies of firms based on their large profits. Dées (2020) ex${ }^{2}$ IEA report, 9 December 2020. Available online:

https://www.iea.org/news/low-carbon-generation-is-becoming-cost-competitive-nea-and-iea-say-innew-report (accessed on 18 March 2021).

${ }^{3}$ Government promotion of "Gogoro". Available online:

https://promotion.gogoro.com/tw/gov-subsidies/?view=subsidy\&city=nantou-country\&model=gogo ro-viva-mix-basic (accessed on 18 March 2021)

${ }^{4}$ Wikipedia, European emission standards. Available online:

https://en.wikipedia.org/wiki/European_emission_standards (accessed on 18 March 2021)

${ }^{5}$ RE100 members and the RE100 Taiwan Report. Available online:

https://www.there100.org/re100-members,

https://www.there100.org/our-work/publications/meeting-demand-supply-renewable-energy-market

-briefing-taiwan. (accessed on 18 March 2021) 
plained the positive relationship between economic growth and pollution emissions. Through empirical data, it was found that higher government environmental management can reduce the external cost of economic growth on environmental pollution, thereby linking government governance with environmental control issues. Fujiwara (2009) discussed how product differences and markets affect government environmental policies in the short- and long-term.

Another type of impact that environmental policies have on the labor and job market was studied by Ulph (1996), Hoel (1997, 1998), Bárcena-Ruiz and Garzón (2003), Bárcena-Ruiz (2011), and Cheng et al. (2019). Bárcena-Ruiz (2011) designed a dual-industry exclusive model with cross-sector pollution, which harms the labor productivity of other industries through environmental pollution, for example, loggers and delivery service personnel through the greenhouse effect, air pollution, and acid rain. This damage is a problem caused by global warming and border conflicts because of transborder pollution. Firms conduct incomplete pollution abatement, and under different labor union systems, they discuss pollution abatement and the impact of productivity on government environmental policies. The above results show that environment policies are related to pollution externalities.

Environmental pollution abatement with respect to awakening the awareness of consumers to green consumption was studied by Ottaviano, Tabuchi, and Thisse (2002), Fujiwara (2009), Yakita and Yamauchi (2011), and Hsu et al. (2017). Most related arguments describe the concerns consumers have regarding the pollution abatement of firms, and control can arouse consumer awareness, thereby increasing the willingness of consumers to pay, but there is no precise discussion of the mechanism linking pollution abatement with the willingness of consumers to pay.

On the contrary, the topic of corporate social responsibility (CSR) has also become a focus of public concern. The theory of CSR is based on economic theory, that is, when enterprises pursue their own economic interests to maximize their own economic benefits, they will obtain the maximum welfare of the whole society. The most suitable actions include the pursuit of economic benefits and compliance with laws, covering specific responses to practical issues of concern to stakeholders such as customers, practitioners, regions, society, and suppliers, and actions to give back to society. Business owners and managers need to consider the stability of their company's sustainable operations and the maintenance of a good reputation when seeking to maximize profits. CSR is a kind of moral or ideological theory, in principle, complying with social ethical behavior and realizing the triple surplus of the enterprise in economy (economy/governance, $G$ ), environment (E), and society (S) to achieve the goal of common sustainable development. According to the definition put forward by the World Business Council for Sustainable Development (WBCSD), "Corporate social responsibility is the continuing commitment by businesses to behave ethically and contribute to economic development while improving the quality of life of the workforce and their families, as well as of the local community and so- 
ciety at large." In the research on CSR, some papers have assumed that firms care about consumer surplus in society in the setting of corporate social responsibility, such as Elfenbein and McManus (2010), Blanco, Ray-Maquieira, and Lozano (2009), Wang et al. (2012), and Chang et al. (2014), which is called consumer-oriented CSR. Other papers, such as those by Jinji (2013) and Liu et al. (2015), have assumed that firms are concerned about the environmental pollution caused by society, which is called environmentally oriented CSR.

In this article, we follow the model setting of Bárcena-Ruiz (2011) and Cheng et al. (2019). The productivity of workers in different industries is believed to be different due to the externalities of pollution. This article adds to the relationship between environmentally oriented CSR and green consumption awareness to highlight the impact of related issues on industrial environmental policies. In particular, the design linking pollution abatement, corporate goals, and the willingness of consumers to pay is an important contribution to existing related research.

The remainder of this paper is arranged as follows: Section 2 discusses the model setting; Section 3 discusses how the output, wages, and environmental policy decisions are determined without CSR; Section 4 discusses how the output, wages, and environmental policy decisions are determined under environmentally oriented CSR; Section 5 discusses the impact of CSR implementation; Section 6 discusses the industrial policies in the long term; Section 7 discusses how the differences in union structure affect the results of CSR; and finally, the conclusions and recommendations are discussed in Section 8.

\section{The Model}

We assumed that there are two environmentally related industries in the domestic market, where industry $X$ is a monopoly and industry $Y$ is an oligopoly of homogeneous $n$ firms. Thus, the market reverse demand can be expressed as:

$$
\begin{gathered}
p_{X}=A-q_{X}+\gamma a_{X} \\
p_{Y}=A-Q_{Y}, Q_{Y}=\sum_{i=1}^{n} q_{i Y},
\end{gathered}
$$

where $p$ is the market price, $A$ is the size of the market, $q$ is the output of a firm, and $\gamma a_{X}$ is the consumer's observation of a firm's environmental governance. Pollution abatement, $a_{X}$, will increase consumers' willingness to pay (WTP), and $\gamma<1$, where $\gamma$ is the elasticity of demand for pollution abatement. Assuming the same cost structure of the firms, they are all functions of wages: $C=w_{k} l_{k}, k=X, i Y$, and $i=1, \cdots, n . l_{k}$ is the amount of labor employed by individual firms and $w_{k}$ is the wage negotiated by individual industrial unions. This paper first discusses the government levying a specific environmental tax on residual pollution under cross-industry external pollution. At that time, a firm's profit and objective function can be described by Equations (2), (3), and (4), ${ }^{6} \mathrm{WBCSD}$ corp report 3/c final (2000, page 3), Available online: https://growthorientedsustainableentrepreneurship.files.wordpress.com/2016/07/csr-wbcsd-csr-prim er.pdf (accessed on 17 March 2021). 
which are the sum of the total revenue minus production costs:

$$
\begin{gathered}
\pi_{X}=p_{X} q_{X}-w_{X} l_{X}-t e_{X}-\frac{d\left(a_{X}\right)^{2}}{2}-k, \\
\pi_{i Y}=p_{Y} q_{i Y}-w_{i Y} l_{i Y}-f, \quad i=1, \cdots, n, \\
\Omega=\pi_{X}+\gamma a_{X} .
\end{gathered}
$$

Industry $X$ conducts pollution abatement level, $a_{X}$, and the pollution abatement cost is a quadratic form $d\left(a_{X}\right)^{2} / 2$. Industry $X$ is a cross-sector pollution industry, which knows that pollution decreases the productivity of other industries, but consumers are aware of and willing to pay higher consumption prices for pollution abatement activities, so industry firm $X$ cares about environmental governance CSR, whose objective function has changed from profit to $\Omega . \gamma$ is the consuming demand elasticity parameter for pollution abatement, where $\gamma<1$ means that its importance is less than that of profit and $\gamma=0$ indicates that a firm is without a CSR state. The government conducts a specific taxation unit, $t$, for a firm's pollution abatement residual amount, $e_{X}\left(e_{X}=q_{X}-a_{X}\right)$. Therefore, the environmental tax expenditure of firm $X$ is $T=t e_{X}$. In order to highlight the production inefficiency of a firm's cross-sector pollution, this paper assumes that the residual pollution of industry firm $X$ will affect the labor productivity of industry $Y$, so we set $q_{X}=l_{X}$ and $q_{i Y}=l_{i Y} /\left(1+\beta e_{X}\right)$, where $\beta>0$, to indicate that pollution affects the productivity parameter of industry $Y$. When $\beta=0$, there is no cross-sector pollution. $k$ and $f$ represent the fixed cost set by the firms.

Individual industries have their own union federations, and wages are determined through consultation between the industrial union and the firms. If the legal wage in the market is $w_{r}$, then the wage strategy obtained by the labor union for its employees is as shown in Equation (5):

$$
\max _{w_{k}} u_{k}=\left(w_{k}-w_{r}\right)^{\theta} l_{k}, \quad k=X, i Y, i=1, \cdots, n,
$$

where $w_{r}$ is the legal (reserved) wage in the market and $\theta$ is the degree to which the union values wages, which is a similar setting to that in the works of Booth (1995), Leahy and Montagna (2000), Lommerud et al. (2003), Bárcena-Ruiz (2003), Haucap and Wey (2004), Bárcena-Ruiz and Garzón (2009), and Choi (2011). We assumed $\theta=1$, which means that the union attaches equal importance to the negotiating wages and the number of employees. To further simplify settings, $w_{r}=0^{7}$.

The objective function of government environmental policy is defined as social welfare, which is the total consumer surplus, producer surplus, the utilities of each union, the environmental pollution damages, and the environmental tax revenues:

$$
S W=\sum_{k=X}^{i Y} C S_{k}+\sum_{k=X}^{i Y} P S_{k}+\sum_{k=X}^{Y} u_{k}-E D+T,
$$

where $C S_{k}$ is the consumer surplus. The environmental pollution damage ${ }^{7}$ We assumed that the reserved wages, $W_{r}$, are zero. Please see Bárcena-Ruiz (2011). 
function $(E D)$ is a quadratic form: $E D=g\left(e_{X}\right)^{2} / 2, g>0$. When $g=0$, the pollution does not harm the environment in any other way except cross-sector pollution, which affects the productivity of industry $Y$. For the convenience of analysis and without loss of generality, we simplified this by setting $d=g=1$.

The social welfare function can be further expressed as Equation (6):

$$
S W=C S_{X}+\sum_{i=1}^{n} C S_{i Y}+\pi_{X}+\sum_{i=1}^{n} \pi_{i Y}+u_{X}+u_{Y}+t e_{X}-\frac{\left(e_{X}\right)^{2}}{2},
$$

In this paper, we followed the model methods of Kossioris et al. (2008) and Kelsey and Milne (2006), where the government decides the environmental tax in the first stage with perfect foresight. The union decides the negotiated wages in the second stage, and the firms decide the quantities and pollution abatement level in the final stage. We used the concepts of backward induction and subgame perfect Nash equilibrium to further illustrate the progress and analysis of the game. The game structure is presented as shown in Figure 1.

\section{The Outputs, Wages, and Environmental Policy Choices without CSR}

\subsection{A Firm's Output Decision}

First, we discuss the issue of a firm's production decision in the third stage of the game and determine the equilibrium outputs of firms $\left(q_{k}^{*}\right)$. Firm $X$ conducts pollution abatement at the same time, so the first-order conditions of the firm's objective functions are:

$$
\begin{gathered}
\frac{\partial \pi_{X}}{\partial q_{X}}=A-2 q_{X}-w_{X}-t=0 \\
\frac{\partial \pi_{X}}{\partial a_{X}}=t-a_{X}=0 \\
\frac{\partial \pi_{i Y}}{\partial q_{i Y}}=A-Q_{Y}-q_{i Y}-w_{i Y}\left(1-\beta a_{X}+\beta q_{X}\right)=0 .
\end{gathered}
$$

Solving the first-order conditions, we obtained the equilibrium outputs and the amount of pollution abatement:

$$
\begin{gathered}
q_{X}=\frac{1}{2}\left(A-t-w_{X}\right), \\
a_{X}=t, \\
q_{i Y}=\frac{2 A-\left(2+A \beta-3 t \beta-\beta w_{X}\right) w_{Y}}{2(1+n)},
\end{gathered}
$$

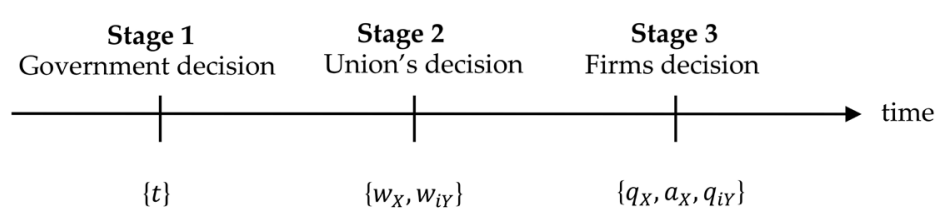

Figure 1. The game structure. Note: the figure is organized by author. 


\subsection{The Union's Decision on the Negotiated Wages}

Next, we returned to the second stage of the game to discuss the issue of the optimal wage determination between individual industrial unions and firms. Substituting the aforementioned results into Equation (5), the objective functions of the unions are:

$$
\begin{gathered}
u_{X}=\frac{1}{2}\left(A-t-w_{X}\right) w_{X}, \\
u_{Y}=\frac{n\left(2+A \beta-3 t \beta-\beta w_{X}\right) w_{Y}\left(2(A+s)-\left(2+A \beta-3 t \beta-\beta w_{X}\right) w_{Y}\right)}{4(1+n)},
\end{gathered}
$$

The first-order conditions of the industrial union objective function are:

$$
\begin{gathered}
\frac{\partial u_{X}}{\partial w_{X}}=\frac{1}{2}\left(A-t-w_{X}\right) w_{X}=0, \\
\frac{\partial u_{Y}}{\partial w_{i Y}}=\frac{n\left(2+A \beta-3 t \beta-\beta w_{X}\right) w_{Y}\left(2 A+\left(-2-A \beta+3 t \beta+\beta w_{X}\right) w_{Y}\right)}{4(1+n)}=0,
\end{gathered}
$$

To solve the first-order conditions together, the optimal negotiated wage levels for the firms are:

$$
\begin{gathered}
w_{X}=\frac{A-t}{2}, \\
w_{i Y}=\frac{2 A}{4+A \beta-5 t \beta} .
\end{gathered}
$$

\subsection{The Decision on Environmental Tax}

Finally, looking back to the first stage of the game, we discuss the government's decision on the optimal environmental tax with the maximum social welfare level. Substituting the result of Equation (8) into Equation (6), the social welfare function can be obtained as:

$$
S W=\frac{1}{16}\left(\frac{A^{2}(3+n(14+9 n))}{(1+n)^{2}}+2 A t-21 t^{2}\right)-(k+n f),
$$

The first- and second-order conditions of maximizing the social welfare function are:

$$
\begin{gathered}
\frac{\partial S W}{\partial t}=\frac{1}{8}(A-21 t)=0, \\
\frac{\partial^{2} S W}{\partial t^{2}}=-\frac{21}{8}<0 .
\end{gathered}
$$

Solving the first-order condition, the optimal environmental tax for a firm can be obtained as:

$$
t^{*}=\frac{A}{21} .
$$

Based on this, Lemma 1 can be obtained. 
Lemma 1:

$$
\begin{gathered}
q_{X}=\frac{5 A}{21}, q_{i Y}=\frac{A}{2+2 n}, \quad a_{X}=\frac{A}{21}, p_{X}=\frac{16 A}{21}, p_{Y}=\frac{A(2+n)}{2(1+n)}, \\
e_{X}=\frac{4 A}{21}, \pi_{X}=\frac{17 A^{2}}{294}-k, \pi_{i Y}=\frac{A^{2}}{4(1+n)^{2}}-f, w_{X}=\frac{10 A}{21}, \\
w_{i Y}=\frac{21 A}{42+8 A \beta}, \quad u_{X}=\frac{50 A^{2}}{441}, \quad u_{Y}=\frac{A^{2} n}{4+4 n}, T=\frac{4 A^{2}}{441}, C S_{X}=\frac{25 A^{2}}{882}, \\
C S_{Y}=\frac{A^{2} n^{2}}{8(1+n)^{2}}, \quad E D=\frac{8 A^{2}}{441}, \quad S W=\frac{A^{2}(32+n(148+95 n))}{168(1+n)^{2}}-(k+n f) .
\end{gathered}
$$

\section{The Outputs, Wages, and Environmental Policy Choices with Environmentally Oriented CSR}

Cross-sector polluters are now paying attention to environmentally oriented CSR. CSR has two effects: First, firms care about the environment, and the importance of reducing profits can improve the social image of firms. Second, caring about the environment increases consumer awareness, and the efforts of firms to carry out pollution abatement can increase the consumer's willingness to pay (WTP).

\subsection{A Firm's Output Decision}

First, we discuss the issue of a firm's production decision in the third stage of the game and determine the equilibrium outputs of the firms $\left(q_{k}^{*}\right)$. Firm $X$ conducts pollution abatement at the same time, so the first-order conditions of the firm's objective functions are:

$$
\begin{gathered}
\frac{\partial \Omega}{\partial q_{X}}=A-t+\gamma a_{X}-2 q_{X}-w_{X}=0, \\
\frac{\partial \Omega}{\partial a_{X}}=t+\gamma-a_{X}+\gamma q_{X}=0, \\
\frac{\partial \pi_{i Y}}{\partial q_{i Y}}=A-Q_{Y}-q_{i Y}-w_{i Y}\left(1-\beta a_{X}+\beta q_{X}\right)=0 .
\end{gathered}
$$

Solving the first-order conditions, we can obtain the equilibrium outputs and the amount of pollution abatement:

$$
\begin{gathered}
q_{X}=\frac{A-t+t \gamma+\gamma^{2}-w_{X}}{2-\gamma^{2}}, \\
a_{X}=\frac{t(2-\gamma)+(2+A) \gamma-\gamma w_{X}}{2-\gamma^{2}}, \\
q_{Y}=\frac{A\left(2-\gamma^{2}\right)-\left(2+A \beta-3 t \beta-(2+A-2 t) \beta \gamma-(1-\beta) \gamma^{2}-\beta(1-\gamma) w_{X}\right) w_{Y}}{(1+n)\left(2-\gamma^{2}\right)} .
\end{gathered}
$$

\subsection{The Union's Decision on the Negotiated Wages}

Next, returning to the second stage of the game, we discuss the issue of the op- 
timal wage determination between individual industrial unions and firms. Substituting the aforementioned results into Equation (5), the objective functions of the unions are:

$$
\begin{gathered}
u_{X}=\frac{\left(A-t(1-\gamma)+\gamma^{2}-w_{X}\right) w_{X}}{2-\gamma^{2}}, \\
u_{Y}=\frac{\left(\begin{array}{l}
n\left(2-t \beta(3-2 \gamma)+A \beta(1-\gamma)-\gamma(\beta(2-\gamma)-\gamma)-\beta(1-\gamma) w_{X}\right) w_{Y}\left(A\left(2-\gamma^{2}\right)\right. \\
\left.+\left(2-t \beta(3-2 \gamma)+A \beta(1-\gamma)-\gamma(\beta(2-\gamma)-\gamma)-\beta(1-\gamma) w_{X}\right) w_{Y}\right)
\end{array}\right)}{(1+n)\left(2-\gamma^{2}\right)^{2}} .
\end{gathered}
$$

The first-order conditions of the industrial union objective function are:

$$
\begin{gathered}
\frac{\partial u_{X}}{\partial w_{X}}=\frac{A+t(-1+\gamma)+\gamma^{2}-2 w_{X}}{2-\gamma^{2}}=0, \\
\frac{\partial u_{Y}}{\partial w_{i Y}}=\frac{\left(\begin{array}{l}
n\left(2-t \beta(3-2 \gamma)+A \beta(1-\gamma)-\gamma(\beta(2-\gamma)-\gamma)-\beta(1-\gamma) w_{X}\right)\left(A\left(2-\gamma^{2}\right)\right. \\
\left.-2\left(2-t \beta(3-2 \gamma)+A \beta(1-\gamma)-\gamma(\beta(2-\gamma)-\gamma)+\beta(1-\gamma) w_{X}\right) w_{Y}\right)
\end{array}\right)}{(1+n)\left(2-\gamma^{2}\right)^{2}}=0,
\end{gathered}
$$

To solve the first-order conditions together, the optimal negotiated wage levels for the firms are:

$$
\begin{gathered}
w_{X}=\frac{1}{2}\left(A-t(1-\gamma)+\gamma^{2}\right), \\
w_{i Y}=\frac{A\left(2-\gamma^{2}\right)}{4+A(\beta-\beta \gamma)+t \beta(-5+\gamma(2+\gamma))+\gamma\left(-2 \gamma+\beta\left(-4+\gamma+\gamma^{2}\right)\right)} .
\end{gathered}
$$

\subsection{The Decision on Environmental Tax}

Finally, returning to the first stage of the game, we discuss the government's decision on the optimal environmental tax with the maximum social welfare level. Substituting the results of Equation (11) back into Equation (6), the social welfare function can be obtained as:

$$
S W=\frac{\left(\begin{array}{l}
4 A(1+n)^{2}\left(t(-1+\gamma)^{2}-(-2+\gamma) \gamma\right)+A^{2}\left(6+2 n(14+9 n)+2(1+n)^{2} \gamma\right. \\
\left.-4\left(1+6 n+4 n^{2}\right) \gamma^{2}+n(4+3 n) \gamma^{4}\right)-2(1+n)^{2}\left(t^{2}(-3+2 \gamma)(-7+\gamma(-1+\gamma(3+\gamma)))\right. \\
\left.+\gamma^{2}\left(16+\gamma\left(-4+\gamma\left(-11+\gamma+2 \gamma^{2}\right)\right)\right)+2 t \gamma(18+\gamma(-7+\gamma(-11+2 \gamma(1+\gamma))))\right)
\end{array}\right)}{8(1+n)^{2}\left(-2+\gamma^{2}\right)^{2}},
$$

The first- and second-order conditions of maximizing the social welfare function are:

$$
\frac{\partial S W}{\partial t}=\frac{A(1-\gamma)^{2}-t(-3+2 \gamma)(-7+\gamma(-1+\gamma(3+\gamma)))+\gamma(-18+\gamma(7+\gamma(11-2 \gamma(1+\gamma))))}{2\left(2-\gamma^{2}\right)^{2}}=0 \text {, }
$$




$$
\frac{\partial^{2} S W}{\partial t^{2}}=-\frac{(3-2 \gamma)(7+\gamma(1-\gamma(3+\gamma)))}{2\left(2-\gamma^{2}\right)^{2}}<0 .
$$

Solving the first-order condition, the optimal environmental tax for a firm can be obtained as:

$$
t^{*}=\frac{A(1-\gamma)^{2}-\gamma(18-\gamma(7+\gamma(11-2 \gamma(1+\gamma))))}{(3-2 \gamma)(7+\gamma(1-\gamma(3+\gamma)))} .
$$

Based on this, Lemma 2 can be obtained.

Lemma 2:

$$
\begin{aligned}
& q_{X}=\frac{2 A(5-\gamma(2+\gamma))+\gamma(9-\gamma(2+3 \gamma))}{2(3-2 \gamma)(7+\gamma(1-\gamma(3+\gamma)))}, \quad q_{i Y}=\frac{A}{2(1+n)}, \\
& a_{X}=\frac{2 A\left(1+\gamma\left(3-\gamma-\gamma^{2}\right)\right)+\gamma(6+\gamma(1-\gamma(2+\gamma)))}{2(3-2 \gamma)(7+\gamma(1-\gamma(3+\gamma)))}, \\
& p_{X}=\frac{2 A\left(4-\gamma-\gamma^{2}\right)^{2}-9 \gamma+(2-\gamma) \gamma^{2}(2+\gamma)^{2}}{2(3-2 \gamma)(7+\gamma(1-\gamma(3+\gamma)))}, \quad p_{Y}=\frac{A(2+n)}{2(1+n)}, \\
& e_{X}=\frac{(1-\gamma)\left(3 \gamma-\gamma^{3}+2 A\left(4-\gamma-\gamma^{2}\right)\right)}{2(3-2 \gamma)(7+\gamma(1-\gamma(3+\gamma)))}, \\
& \pi_{X}=\frac{\left(\begin{array}{l}
4 A^{2}(51-\gamma(44+\gamma(31-\gamma(24+\gamma(9-\gamma(4+\gamma)))))) \\
+4 A \gamma(54+\gamma(-180+\gamma(67+\gamma(118+\gamma(-44+\gamma(-34+\gamma(7+4 \gamma))))))) \\
+\gamma^{2}(-306+\gamma(12+\gamma(359+\gamma(52+\gamma(-156+\gamma(-40+\gamma(23+8 \gamma)))))))
\end{array}\right)}{8(3-2 \gamma)^{2}(-7+\gamma(-1+\gamma(3+\gamma)))^{2}}-k, \\
& \pi_{i Y}=\frac{A^{2}}{4(1+n)^{2}}-f, \quad w_{X}=\frac{\left(2-\gamma^{2}\right)(2 A(5-\gamma(2+\gamma))-\gamma(9-\gamma(2+3 \gamma)))}{2(3-2 \gamma)(7+\gamma(1-\gamma(3+\gamma)))}, \\
& w_{i Y}=\frac{A(3-2 \gamma)(7+\gamma(1-\gamma(3+\gamma)))}{42+2 A \beta\left(4-5 \gamma+\gamma^{3}\right)+\gamma\left(-22+\beta(-1+\gamma)\left(-3+\gamma^{2}\right)+2 \gamma(-11+\gamma(3+2 \gamma))\right)}, \\
& u_{X}=\frac{\left(2-\gamma^{2}\right)(2 A(-5+\gamma(2+\gamma))+\gamma(-9+\gamma(2+3 \gamma)))^{2}}{4(3-2 \gamma)^{2}(7+\gamma(1-\gamma(3+\gamma)))^{2}}, u_{Y}=\frac{A^{2} n}{4(1+n)}, \\
& T=\frac{(1-\gamma)\left(-3 \gamma+\gamma^{3}+2 A\left(-4+\gamma+\gamma^{2}\right)\right)\left(-A(-1+\gamma)^{2}+\gamma(18+\gamma(-7+\gamma(-11+2 \gamma(1+\gamma))))\right)}{2(3-2 \gamma)^{2}(7+\gamma(1-\gamma(3+\gamma)))^{2}}, \\
& C S_{X}=\frac{(2 A(-5+\gamma(2+\gamma))+\gamma(-9+\gamma(2+3 \gamma)))^{2}}{8(3-2 \gamma)^{2}(-7+\gamma(-1+\gamma(3+\gamma)))^{2}}, C S_{Y}=\frac{A^{2} n^{2}}{8(1+n)^{2}},
\end{aligned}
$$




$$
\begin{gathered}
E D=\frac{(1-\gamma)^{2}\left(-3 \gamma+\gamma^{3}+2 A\left(-4+\gamma+\gamma^{2}\right)\right)^{2}}{8(3-2 \gamma)^{2}(7+\gamma(1-\gamma(3+\gamma)))^{2}}, \\
S W=\frac{\left(\begin{array}{l}
2(1+n)^{2}(-1+\gamma) \gamma^{2}(3+\gamma)-8 A(1+n)^{2} \gamma\left(-3+\gamma^{2}\right) \\
+A^{2}\left(-8\left(-4+\gamma+\gamma^{2}\right)+n^{2}\left(95+\gamma\left(-41+\gamma\left(-41+9 \gamma+6 \gamma^{2}\right)\right)\right)\right. \\
+4 n(37+\gamma(-15+\gamma(-15+\gamma(3+2 \gamma)))))
\end{array}\right)}{8(1+n)^{2}(3-2 \gamma)(7+\gamma(1-\gamma(3+\gamma)))}-(k+n f) .
\end{gathered}
$$

\section{The Impact of Environmentally Oriented CSR}

By comparing the analysis results of Sections 3 and 4, the levels of environmental tax are as follows:

$$
\begin{gathered}
t^{N}=\frac{A}{21}, \\
t^{R}=\frac{A(1-\gamma)^{2}-\gamma(18-\gamma(7+\gamma(11-2 \gamma(1+\gamma))))}{(3-2 \gamma)(7+\gamma(1-\gamma(3+\gamma)))},
\end{gathered}
$$

where $N$ indicates the result under no CSR and R indicates the result under CSR. Comparing the two results, we can see that under the condition of $0<\gamma<1$ : (For comparison results, please see Appendix A.)

$$
t^{R}-t^{N}=\frac{A(1-\gamma)^{2}-\gamma(18-\gamma(7+\gamma(11-2 \gamma(1+\gamma))))}{(3-2 \gamma)(7+\gamma(1-\gamma(3+\gamma)))}-\frac{A}{21}<0,
$$

Therefore, the government's optimal environmental tax rate will be lowered when polluting firms implement environmentally oriented CSR and increase consumers' willingness to pay.

A firm's pollution abatement residual levels are as follows:

$$
\begin{gathered}
e_{X}^{N}=\frac{4 A}{21}, \\
e_{X}^{R}=\frac{(1-\gamma)\left(3 \gamma-\gamma^{3}+2 A\left(4-\gamma-\gamma^{2}\right)\right)}{2(3-2 \gamma)(7+\gamma(1-\gamma(3+\gamma)))},
\end{gathered}
$$

To compare the two results in a similar manner, the following can be obtained:

$$
e_{X}^{R}-e_{X}^{N}=\frac{(1-\gamma)\left(3 \gamma-\gamma^{3}+2 A\left(4-\gamma-\gamma^{2}\right)\right)}{2(3-2 \gamma)(7+\gamma(1-\gamma(3+\gamma)))}-\frac{4 A}{21}<0,
$$

Therefore, in the implementation of environmentally oriented CSR and the increase in the WTP of consumers by the polluting firm, the residual pollution abatement level of a firm will be reduced, which is beneficial for environmental protection. Based on this, Proposition 1 can be obtained.

Proposition 1: 
If polluting firms implement environmentally oriented CSR and increase consumers WTP accordingly, the government's optimal environmental tax rate and the firms residual pollution abatement level will both be reduced, which will be beneficial for environmental protection.

Proof: According to the aforementioned analysis. We can check it in appendix A.

The relationship between the pollution abatement level and the optimal environmental tax rate can explain the relevant mechanism introduced by CSR. When a firm does not consider CSR, the traditional literature (Bárcena-Ruiz and Garzón (2003) and Bárcena-Ruiz (2011)) demonstrates that the optimal environmental tax rate remains at the Pigou tax level, namely, $t^{N}=a_{X}^{N}$. When a polluting firm considers environmentally oriented CSR, consumers' WTP improves:

$$
a_{X}^{R}-t^{R}=\frac{\gamma(42+2 A(5-\gamma(2+\gamma))-\gamma(13+\gamma(24-\gamma(3+4 \gamma))))}{2(3-2 \gamma)(7+\gamma(1-\gamma(3+\gamma)))}>0,
$$

Therefore, the firm will cause the pollution abatement level to exceed the optimal environmental tax rate and decouple from the Pigou tax. This mechanism also reduces the optimal environmental tax rate and the residual pollution abatement level.

A comparison can then be made between the impact that environmentally oriented CSR has on the consumer surplus, firm profits, union utilities, tax revenue, environmental pollution damage level, and social welfare level. According to a comparison of consumer surplus, under the condition of $0<\gamma<1$ :

$$
C S^{R}-C S^{N}=\frac{(2 A(-5+\gamma(2+\gamma))+\gamma(-9+\gamma(2+3 \gamma)))^{2}}{8(3-2 \gamma)^{2}(7+\gamma(1-\gamma(3+\gamma)))^{2}}-\frac{25 A^{2}}{882}>0,
$$

If a polluting firm implements environmentally oriented CSR and increases consumers' WTP, the consumer surplus will increase.

According to the comparison of firms' profits, under the condition of $0<\gamma<1:$

$$
\pi_{X}^{R}-\pi_{X}^{N}=\frac{\left(\begin{array}{l}
4 A^{2}(51-\gamma(44+\gamma(31-\gamma(24+\gamma(9-\gamma(4+\gamma)))))) \\
+4 A \gamma(54+\gamma(-180+\gamma(67+\gamma(118+\gamma(-44+\gamma(-34+\gamma(7+4 \gamma))))))) \\
+\gamma^{2}(-306+\gamma(12+\gamma(359+\gamma(52+\gamma(-156+\gamma(-40+\gamma(23+8 \gamma)))))))
\end{array}\right)}{8(3-2 \gamma)^{2}(-7+\gamma(-1+\gamma(3+\gamma)))^{2}}-\frac{17 A^{2}}{294}>0,
$$

and

$$
\pi_{i Y}^{R}-\pi_{i Y}^{N}=0,
$$

If a polluting firm implements environmentally oriented CSR and increases consumers' WTP, the profits from its own industry firm will increase, but there 
will be no effect on the profits of industry firm $Y$, whose productivity is affected by pollution.

According to the comparison of union utilities, under the condition of $0<\gamma<1$ :

$$
u_{X}^{R}-u_{X}^{N}=\frac{\left(2-\gamma^{2}\right)(2 A(-5+\gamma(2+\gamma))+\gamma(-9+\gamma(2+3 \gamma)))^{2}}{4(3-2 \gamma)^{2}(-7+\gamma(-1+\gamma(3+\gamma)))^{2}}-\frac{50 A^{2}}{441}>0,
$$

and

$$
u_{Y}^{R}-u_{Y}^{N}=0,
$$

If a polluting firm implements environmentally oriented CSR and increases consumers' WTP, the union utility of its own industry $X$ will increase, but there will be no effect on the polluted industry union $Y$.

According to a comparison of the environmental tax revenue and the environmental pollution damage level, under the condition of $0<\gamma<1$ :

$$
T^{R}-T^{N}=\frac{(1-\gamma)\left(-3 \gamma+\gamma^{3}+2 A\left(-4+\gamma+\gamma^{2}\right)\right)\left(A(1-\gamma)^{2}-\gamma(18-\gamma(7+\gamma(11-2 \gamma(1+\gamma))))\right)}{2(3-2 \gamma)^{2}(-7+\gamma(-1+\gamma(3+\gamma)))^{2}}-\frac{4 A^{2}}{441}<0
$$

and

$$
E D^{R}-E D^{N}=\frac{(-1+\gamma)^{2}\left(-3 \gamma+\gamma^{3}+2 A\left(-4+\gamma+\gamma^{2}\right)\right)^{2}}{8(3-2 \gamma)^{2}(-7+\gamma(-1+\gamma(3+\gamma)))^{2}}-\frac{8 A^{2}}{441}<0,
$$

If a polluting firm implements environmentally oriented CSR and increases consumers' WTP, the environmental pollution damage level will increase, but the government's tax revenue will decrease.

According to the comparison of social welfare levels, under the condition of $0<\gamma<1$ :

$$
S W^{R}-S W^{N}=\frac{\gamma\left(A^{2}(92+4 \gamma(23-4 \gamma(3+2 \gamma)))-21(1-\gamma) \gamma(3+\gamma)+84 A\left(3-\gamma^{2}\right)\right)}{84(3-2 \gamma)(7+\gamma(1-\gamma(3+\gamma)))}>0,
$$

If a polluting firm implements environmentally oriented CSR and increases consumers' WTP, the social welfare level will improve.

Based on this, Proposition 2 can be obtained.

\section{Proposition 2:}

If a polluting firm implements environmentally oriented CSR and increases consumers 'WTP accordingly, a firm's profit and the union's utility will increase, as well as the overall consumer surplus and the social welfare level; however, there will be no effect on the profit and union utility of firms whose productivity is reduced by pollution.

Proof: According to the aforementioned analysis. We can check it in appendix A.

The above results are understandable for industry $X$, who causes cross-sector 
pollution, but for the CSR neutrality of industry $Y$, we can illustrate the results through the following analysis. Because industry firm $X$ reduces the residual pollution abatement level, the productivity of the workers of industry firm $Y$ will increase. At the same time, through the negotiation of the union, the wages of industry $Y$ will also increase, that is:

$$
w_{i Y}^{R}-w_{i Y}^{N}=\frac{A(3-2 \gamma)(7+\gamma(1-\gamma(3+\gamma)))}{42+2 A \beta\left(4-5 \gamma+\gamma^{3}\right)-\gamma\left(22-\beta(1-\gamma)\left(3-\gamma^{2}\right)+2 \gamma(11-\gamma(3+2 \gamma))\right)}-\frac{21 A}{42+8 A \beta}>0 .
$$

Although the productivity of the workers of industry $Y$ increases, it is completely reflected in the wages, and the profits of industry firm $Y$ and the utility of the union are not affected at all.

The wages of industry $X$ can also be understood by the following formula:

$$
w_{X}^{R}-w_{X}^{N}=\frac{\left(2-\gamma^{2}\right)(2 A(5-\gamma(2+\gamma))+\gamma(9-\gamma(2+3 \gamma)))}{2(3-2 \gamma)(7+\gamma(1-\gamma(3+\gamma)))}-\frac{10 A}{21}>0 .
$$

It can be seen that the wages negotiated by the unions of all firms will increase due to the introduction of CSR, which is conducive to worker welfare. At this point, we can obtain the impact of environmentally oriented and consumer-aware CSR as follows:

First, the government's optimal environmental tax rate and the residual pollution abatement level of a firm will decrease, which is conducive to environmental protection. Second, under the influence of CSR, the negotiated wages of all firms will increase.

Finally, the CSR will increase a firm's profits and the union's utilities of its own industrial firm, as well as the overall consumer surplus and the social welfare level; however, there will be no effect on the profit and union utility of firms whose productivity is reduced by pollution.

\section{Long-Term Industrial and Environmental Policy}

In this section, we continue to discuss that with access to industry market $Y$ in the long term, the excess profits of its firms will be squeezed to zero profits. Herein, we discuss the long-term impact of the environmentally oriented CSR of a cross-border-polluting firm on the polluted industry market.

\subsection{A Firm's Output Decision in the Long Term}

First, we discuss the issue of a firm's production decision in the third stage of the game and determine the equilibrium outputs of the firms. Industry firm $X$ conducts pollution abatement at the same time, so the first-order conditions of the firm's objective functions are as shown in Section 4.1.

The market opens the free entry of industry firm $Y$ in the long term, and we can add the zero-profit conditions as $\pi_{i Y}=0$. To solve the first-order conditions together, the optimal output, the pollution abatement level, and the number of firms allowed in the market are: 


$$
\begin{gathered}
q_{X}=\frac{A-t+t \gamma+\gamma^{2}-w_{X}}{2-\gamma^{2}}, \\
a_{X}=\frac{t(2-\gamma)+(2+A) \gamma-\gamma w_{X}}{2-\gamma^{2}}, \\
q_{i Y}=\sqrt{f}, \\
n=\frac{(A-\sqrt{f})\left(2-\gamma^{2}\right)-\left(2+A \beta-3 t \beta-(2+A-2 t) \beta \gamma-(1-\beta) \gamma^{2}-\beta(1-\gamma) w_{X}\right) w_{Y}}{\sqrt{f}\left(2-\gamma^{2}\right)} .
\end{gathered}
$$

\subsection{The Union's Decision on the Negotiated Wages in the Long Term}

Next, returning to the second stage of the game, we discuss the issue of the optimal wage determination between individual industrial unions and firms. Substituting the aforementioned results into Equation (5), the objective functions of the union are:

$$
\begin{gathered}
u_{X}=\frac{\left(A-t(1-\gamma)+\gamma^{2}-w_{X}\right) w_{X}}{2-\gamma^{2}}, \\
u_{Y}=\frac{\left(\begin{array}{l}
\left(2-t \beta(3-2 \gamma)+A \beta(1-\gamma)-\gamma(\beta(2-\gamma)-\gamma)-\beta(1-\gamma) w_{X}\right) w_{Y}\left((A-\sqrt{f})\left(2-\gamma^{2}\right)\right. \\
\left.+\left(-2+t \beta(3-2 \gamma)-A \beta(1-\gamma)+\gamma(\beta(2-\gamma)+\gamma)+\beta(1-\gamma) w_{X}\right) w_{Y}\right)
\end{array}\right)}{\left(2-\gamma^{2}\right)^{2}},
\end{gathered}
$$

The first-order conditions of the industrial union objective function are:

$$
\begin{gathered}
\frac{\partial u_{X}}{\partial w_{X}}=\frac{A-t(1-\gamma)+\gamma^{2}-2 w_{X}}{2-\gamma^{2}}=0, \\
\frac{\partial u_{Y}}{\partial w_{i Y}}=\frac{\left(\begin{array}{l}
\left(2-t \beta(3-2 \gamma)+A \beta(1-\gamma)-\gamma(\beta(2-\gamma)-\gamma)-\beta(1-\gamma) w_{X}\right)\left((A-\sqrt{f})\left(2-\gamma^{2}\right)\right. \\
\left.+\left(-2+t \beta(3-2 \gamma)-A \beta(1-\gamma)+\gamma(\beta(2-\gamma)+\gamma)+\beta(1-\gamma) w_{X}\right) w_{Y}\right)
\end{array}\right)}{\left(2-\gamma^{2}\right)^{2}}=0,
\end{gathered}
$$

Solving the first-order conditions together, the optimal negotiated wage levels for the firms are:

$$
\begin{gathered}
w_{X}=\frac{1}{2}\left(A-t(1-\gamma)+\gamma^{2}\right), \\
w_{i Y}=\frac{(A-\sqrt{f})\left(2-\gamma^{2}\right)}{4+A(\beta-\beta \gamma)+t \beta(-5+\gamma(2+\gamma))+\gamma\left(-2 \gamma+\beta\left(-4+\gamma+\gamma^{2}\right)\right)} .
\end{gathered}
$$

When comparing the results of Equations (14) and (11), it is clear that under the same environmental tax rate, the negotiated wages of industry union $Y$ for the long-term market will be lower than those for the short-term market.

\subsection{The Decision on the Environmental Tax in the Long Term}

Finally, returning to the first stage of the game, we discuss the government's de- 
cision on the optimal environmental tax with the maximum social welfare level. By substituting the results of Equation (14) into Equation (6), the social welfare function can be obtained as:

$$
\begin{aligned}
S W= & \frac{1}{8}\left(6+3 A^{2}-6 A \sqrt{f}+3 f-8 t-4 t^{2}-2(1+4 t) \gamma-4 \gamma^{2}\right. \\
& +\frac{2\left(-(2+A)^{2}+6(2+A) t-7 t^{2}+\left((2+A)^{2}-4(2+A) t+5 t^{2}\right) \gamma\right)}{\left(2-\gamma^{2}\right)^{2}} \\
& \left.+\frac{4 A^{2}-8+4 A(1-t)+2 t(2-3 t(1-\gamma)-6 \gamma)}{2-\gamma^{2}}\right)-k
\end{aligned}
$$

The first- and second-order conditions of maximizing the social welfare function are:

$$
\begin{gathered}
\frac{\partial S W}{\partial t}=\frac{A(1-\gamma)^{2}-t(3-2 \gamma)(7+\gamma(1-\gamma(3+\gamma)))-\gamma(18-\gamma(7+\gamma(11-2 \gamma(1+\gamma))))}{2\left(2-\gamma^{2}\right)^{2}}=0, \\
\frac{\partial^{2} S W}{\partial t^{2}}=-\frac{(3-2 \gamma)(7+\gamma(1-\gamma(3+\gamma)))}{2\left(2-\gamma^{2}\right)^{2}}<0,
\end{gathered}
$$

To solve the first-order condition, the optimal environmental tax for a firm can be obtained as:

$$
t^{*}=\frac{A(1-\gamma)^{2}-\gamma(18-\gamma(7+\gamma(11-2 \gamma(1+\gamma))))}{(3-2 \gamma)(7+\gamma(1-\gamma(3+\gamma)))} .
$$

The above equation is identical to Equation (12); that is, the long-term market entry of polluted firms does not affect the government's optimal environmental policy.

Based on this, Lemma 3 can be obtained.

Lemma 3:

$$
\begin{gathered}
q_{X}=\frac{2 A(5-\gamma(2+\gamma))+\gamma(9-\gamma(2+3 \gamma))}{2(3-2 \gamma)(7+\gamma(1-\gamma(3+\gamma)))}, q_{i Y}=\sqrt{f} \\
a_{X}=\frac{2 A\left(1+\gamma\left(3-\gamma-\gamma^{2}\right)\right)+\gamma(6+\gamma(1-\gamma(2+\gamma)))}{2(3-2 \gamma)(7+\gamma(1-\gamma(3+\gamma)))}, \\
p_{X}=\frac{2 A\left(4-\gamma-\gamma^{2}\right)^{2}-9 \gamma+(2-\gamma) \gamma^{2}(2+\gamma)^{2}}{2(3-2 \gamma)(7+\gamma(1-\gamma(3+\gamma)))} \\
p_{Y}=\frac{1}{2}(A+\sqrt{f}) \\
e_{X}=\frac{(1-\gamma)\left(3 \gamma-\gamma^{3}+2 A\left(4-\gamma-\gamma^{2}\right)\right)}{2(3-2 \gamma)(7+\gamma(1-\gamma(3+\gamma)))}
\end{gathered}
$$




$$
\begin{aligned}
& \pi_{X}=\frac{\left(\begin{array}{l}
4 A^{2}(51-\gamma(44+\gamma(31-\gamma(24+\gamma(9-\gamma(4+\gamma)))))) \\
+4 A \gamma(54+\gamma(-180+\gamma(67+\gamma(118+\gamma(-44+\gamma(-34+\gamma(7+4 \gamma))))))) \\
+\gamma^{2}(-306+\gamma(12+\gamma(359+\gamma(52+\gamma(-156+\gamma(-40+\gamma(23+8 \gamma)))))))
\end{array}\right)}{8(3-2 \gamma)^{2}(-7+\gamma(-1+\gamma(3+\gamma)))^{2}}-k, \\
& \pi_{i Y}=0, \quad w_{X}=\frac{\left(2-\gamma^{2}\right)(2 A(5-\gamma(2+\gamma))-\gamma(9-\gamma(2+3 \gamma)))}{2(3-2 \gamma)(7+\gamma(1-\gamma(3+\gamma)))}, \\
& w_{i Y}=\frac{(A-\sqrt{f})(3-2 \gamma)(7+\gamma(1-\gamma(3+\gamma)))}{42+2 A \beta\left(4-5 \gamma+\gamma^{3}\right)+\gamma\left(-22+\beta(-1+\gamma)\left(-3+\gamma^{2}\right)+2 \gamma(-11+\gamma(3+2 \gamma))\right)}, \\
& u_{X}=\frac{\left(2-\gamma^{2}\right)(2 A(-5+\gamma(2+\gamma))+\gamma(-9+\gamma(2+3 \gamma)))^{2}}{4(3-2 \gamma)^{2}(7+\gamma(1-\gamma(3+\gamma)))^{2}}, u_{Y}=\frac{1}{4}(A-\sqrt{f})^{2} \\
& T=\frac{(1-\gamma)\left(-3 \gamma+\gamma^{3}+2 A\left(-4+\gamma+\gamma^{2}\right)\right)\left(-A(-1+\gamma)^{2}+\gamma(18+\gamma(-7+\gamma(-11+2 \gamma(1+\gamma))))\right)}{2(3-2 \gamma)^{2}(7+\gamma(1-\gamma(3+\gamma)))^{2}}, \\
& C S_{X}=\frac{(2 A(-5+\gamma(2+\gamma))+\gamma(-9+\gamma(2+3 \gamma)))^{2}}{8(3-2 \gamma)^{2}(-7+\gamma(-1+\gamma(3+\gamma)))^{2}}, C S_{Y}=\frac{1}{8}(A-\sqrt{f})^{2} \text {, } \\
& E D=\frac{(1-\gamma)^{2}\left(-3 \gamma+\gamma^{3}+2 A\left(-4+\gamma+\gamma^{2}\right)\right)^{2}}{8(3-2 \gamma)^{2}(7+\gamma(1-\gamma(3+\gamma)))^{2}}, \quad n=\frac{1}{2}\left(\frac{A}{\sqrt{f}}-1\right) \\
& S W=\frac{13\left(1+3(A-\sqrt{f})^{2}\right)-\frac{(9+4 A)^{2}}{3-2 \gamma}+\frac{2\left(49+\gamma(70+17 \gamma)+4 A^{2}(22+\gamma(11+\gamma))+4 A(21+\gamma(30+11 \gamma))\right.}{7+\gamma(1-\gamma(3+\gamma))}}{104} .
\end{aligned}
$$

Accordingly, proposition 3 can be obtained.

\section{Proposition 3:}

As the pollution-damaged industry market opens up in the long term, the government's environmental tax will be no different from that of the short-term case, and the behavior of the firms in the polluting industry will not be affected; however, the negotiated wages of the labor unions of the polluted industries will drop.

Proof: We can compare with the results in lemma 2 and lemma 3.

It can be seen from the introduction of CSR that the negotiated wages of unions will increase in all industries, while the market opening of industry $Y$ in the long term will reduce the negotiated wages of its own union and offset the effect of the CSR of industry firm $X$.

\section{Extended Discussion-The United Union Structure}

In the previous section, we got that the CSR of polluters will increase wages, the 
utility of their own firms, and the industrial union; however, there will be no effect on the utility of the polluted industry firms and unions. This section will extend the model to a united union structure. If two industries have a common union federation, we will try to understand whether the CSR effect is different due to the different union structures. In this case, a cross-industry general union was established to negotiate the wages of individual industries, for which Equation (5) became Equation (15):

$$
\max _{w_{k}} U=u_{X}+u_{Y}, \quad k=X, Y,
$$

The results of further analysis show that the negotiated wages and union utility of each industry before and after CSR did not change due to changes in the union structure. (The results are the same as Lemma 1 and Lemma 2. Please see Appendix B) That is, with the increase in all negotiated wages from CSR and the increase in the utility of individual unions in industry $X$, which, when combined, formed the overall result, the utility of the union federation will increase, and there will be no difference in the negotiated wages and the overall utilities of the union.

\section{Conclusion}

In this paper, we established a cross-industry pollution externality design and used the three-stage game analysis framework to discuss the issues linked to firms' output, labor unions' negotiation wages, and the government's optimal environmental tax. We obtained the following results: First, considering environmentally oriented CSR, the government's optimal environmental tax rate and firms' residual pollution abatement level will decrease, which is conducive to environmental protection. Second, under the influence of environmentally oriented CSR, the negotiated wages of all firms will increase. Third, environmentally oriented CSR will increase the profits and union utility of its own industry firms, as well as the overall consumer surplus and the social welfare level; however, there will be no effect on the profit and union utility of firms whose productivity is reduced by pollution. Fourth, when the pollution-damaged industry market has completely free entry in the long term, the government's environmental tax will be identical to that of the short-term case, and the behavior of firms in the polluting industry will not be affected; however, the negotiated wages of the labor unions of the polluted industries will drop. Finally, when the structure of unions is changed, the production behavior of all firms, the utilities of unions, and the government's environmental policies will not change.

Based on these results, we can gain an understanding of the linkage between pollution abatement and consumption awareness, to which consumers now attach great importance. Through the efforts of branding and marketing, coupled with the persistence of corporate image and corporate social responsibility, we can achieve a firm's sustainable operation and environmental friendliness, and can enhance the corporate public welfare image. We can also understand that firms care about corporate social responsibility and achieve different results by 
focusing on profits, which can help us recognize the operations of the real world.

\section{Conflicts of Interest}

The author declares no conflicts of interest regarding the publication of this paper.

\section{References}

Bárcena-Ruiz, J. C. (2003). Politically Preferred Wage Bargaining Structures. European Journal of Political Economy, 19, 341-353.

https://doi.org/10.1016/S0176-2680(02)00173-8

Bárcena-Ruiz, J. C. (2011). Production Externality and Productivity of Labor. Revista de Economia Publica, 196, 65-78.

Bárcena-Ruiz, J. C., \& Garzón, M. B. (2003). Strategic Environmental Standards, Wage Incomes and the Location of Polluting Firms. Environmental and Resource Economics, 24, 121-139. https://doi.org/10.1023/A:1022837008712

Bárcena-Ruiz, J. C., \& Garzón, M. B. (2009). Environmental Taxes and Wage Setting Structure. Prague Economic Papers, 4, 353-365. https://doi.org/10.18267/j.pep.359

Blanco, E., Ray-Maquieira, J., \& Lozano, J. (2009). The Economic Impacts of Voluntary Environmental Performance of Firms: A Critical Review. Journal of Economic Surveys, 23, 462-502. https://doi.org/10.1111/j.1467-6419.2008.00569.x

Booth, A. (1995). The Economics of the Trade Union. Cambridge, New York: Cambridge University Press.

Canton, J., Soubeyran, A., \& Stahn, H. (2008). Environmental Taxation and Vertical Cournot Oligopolies: How Eco-Industries Matter. Environmental and Resource Economics, 40, 369-382. https://doi.org/10.1007/s10640-007-9158-8

Cato, S. (2010). Emission Taxes and Optimal Refunding Schemes with Endogenous Market Structure. Environmental Resource Economics, 46, 275-280.

https://doi.org/10.1007/s10640-009-9340-2

Chang, Y. M., Chen, H. Y., Wang, L. F. S., \& Wu, S. J. (2014). Corporate Social Responsibility and International Competition: A Welfare Analysis. Review of International Economics, 22, 625-638. https://doi.org/10.1111/roie.12117

Cheng, K. F., Tsai, C. S., Hsu, C. C., Lin, S. C., Tsai, T. C., \& Lee, J. Y. (2019). Emission Tax and Compensation Subsidy with Cross-Industry Pollution. Sustainability, 11, 1-23. https://doi.org/10.3390/su11040998

Choi, K. (2011). Unions, Government's Preference, and Privatization. Economic Modeling, 28, 2502-2508. https://doi.org/10.1016/j.econmod.2011.06.025

Damania, D. (1996). Pollution Taxes and Pollution Abatement in an Oligopoly Supergame. Journal of Environmental Economics and Management, 30, 323-336. https://doi.org/10.1006/jeem.1996.0022

Dées, S. (2020). Assessing the Role of Institutions in Limiting the Environmental Externalities of Economic Growth. Environmental and Resource Economics, 76, 429-445. https://doi.org/10.1007/s10640-020-00432-1

Elfenbein, D. W., \& McManus, B. (2010). A Greater Price for a Greater Good? Evidence That Consumers Pay More for Charity-Linked Products. American Economic Journal: Economic Policy, 2, 28-60. https://doi.org/10.1257/pol.2.2.28

Fujiwara, K. (2009). Environmental Policies in a Differentiated Oligopoly Revisited. Resource and Energy Economics, 31, 239-247. 
https://doi.org/10.1016/j.reseneeco.2009.03.002

Haucap, J., \& Wey, C. (2004). Unionisation Structures and Innovation Incentives. Economic Journal, 114, C149-C165. https://doi.org/10.1111/j.0013-0133.2004.00203.x

Hoel, M. (1997). Coordination of Environmental Policy for Transboundary Environmental Problems. Journal of Public Economics, 66, 199-224. https://doi.org/10.1016/S0047-2727(97)00042-X

Hoel, M. (1998). Emission Taxes versus Other Environmental Policies. Scandinavian Journal of Economics, 100, 79-104. https://doi.org/10.1111/1467-9442.00091

Hsu, C. C., Lee, J. Y., \& Wang, L. F. S. (2017). Consumers Awareness and Environmental Policy in Differentiated Mixed Oligopoly. International Review of Economics and Finance, 51, 444-454. https://doi.org/10.1016/j.iref.2017.07.001

Jinji, N. (2013). Is Corporate Environmentalism Good for Domestic Welfare? Review of International Economics, 21, 901-911. https://doi.org/10.1111/roie.12078

Kato, K. (2006). Can Allowing to Trade Permits Enhance Welfare in Mixed Oligopoly? Journal of Economics, 88, 263-283. https://doi.org/10.1007/s00712-006-0206-6

Katsoulacos, Y., \& Xepapadeas, A. (1995). Environmental Policy under Oligopoly with Endogenous Market Structure. Scandinavian Journal of Economics, 97, 411-420. https://doi.org/10.2307/3440871

Kelsey, D., \& Milne, F. (2006). Externalities, Monopoly and the Objective Function of the Firm. Economic Theory, 29, 565-589. https://doi.org/10.1007/s00199-005-0036-8

Kossioris, M., Plexousakis, A., Xepapadeas, A., \& de Zeeuw, K.-G. M. (2008). Feedback Nash Equilibria for Non-Linear Differential Games in Pollution Control. Journal of Economic Dynamics and Control, 32, 1312-1331. https://doi.org/10.1016/j.jedc.2007.05.008

Lahiri, S., \& Ono, Y. (2007). Relative Emission Standard versus Tax under Oligopoly: The Role of Free Entry. Journal of Economics, 91, 107-128.

https://doi.org/10.1007/s00712-006-0243-1

Laroche, M., Bergeron, J., \& Barbaro-Forleo, G. (2001). Targeting Consumers Who Are Willing to Pay More for Environmentally Friendly Product. Journal of Consumer Marketing, 18, 503-520. https://doi.org/10.1108/EUM0000000006155

Leahy, D., \& Montagna, C. (2000). Unionisation and Foreign Direct Investment: Challenging Conventional Wisdom? Economic Journal, 110, C80-C92. https://doi.org/10.1111/1468-0297.00522

Lehmann, P. (2010). Justifying a Policy Mix for Pollution Control: A Review of Economic Literature. Journal of Economic Surveys, 26, 71-97. https://doi.org/10.1111/j.1467-6419.2010.00628.x

Liu, C. C., Wang, L. F. S., \& Lee, S. H. (2015). Strategic Environmental Corporate Social Responsibility in a Differentiated Duopoly Market. Economics Letters, 129, 108-111. https://doi.org/10.1016/j.econlet.2015.02.027

Lommerud, K. E., Meland, F., \& Sorgard, L. (2003). Unionised Oligopoly, Trade Liberalisation and Location Choice. Economic Journal, 113, 782-800.

https://doi.org/10.1111/1468-0297.t01-1-00154

Ottaviano, G. I. P., Tabuchi, T., \& Thisse, J. (2002). Agglomeration and Trade Revisited. International Economic Review, 43, 409-436. https://doi.org/10.1111/1468-2354.t01-1-00021

Simpson, R. D. (1995). Optimal Pollution Taxation in a Cournot Duopoly. Environmental and Resource Economics, 6, 359-369. https://doi.org/10.1007/BF00691819

Ulph, A. (1996). Environmental Policy and International Trade When Governments and 
Producers Act Strategically. Journal of Environmental Economics and Management, 30, 265-281. https://doi.org/10.1006/jeem.1996.0018

Wang, L. F. S., Wang, Y. C., \& Zhao, L. (2012). Tariff Policy and Welfare in an International Duopoly with Consumer-Friendly Initiative. Bulletin of Economic Research, 64, 56-64. https://doi.org/10.1111/j.1467-8586.2010.00382.x

Yakita, A., \& Yamauchi, H. (2011). Environmental Awareness and Environmental R\&D Spillovers in Differentiated Duopoly. Research in Economics, 65, 137-143.

https://doi.org/10.1016/j.rie.2010.02.003 


\section{Appendix A}

If the market size $A$ is large enough (let $A=100$ ) and the elasticity of the demand for pollution abatement for $\gamma$ is between 1 and 0 , we can obtain the results presented in Section 5. The graphical analysis of the numerical simulation in the gap of environmental tax, residual of pollution abatement level, firm's profit, union utility, consumer surplus, environmental pollution damages, environmental taxes revenues, and social welfare is presented as shown in Figure A1.

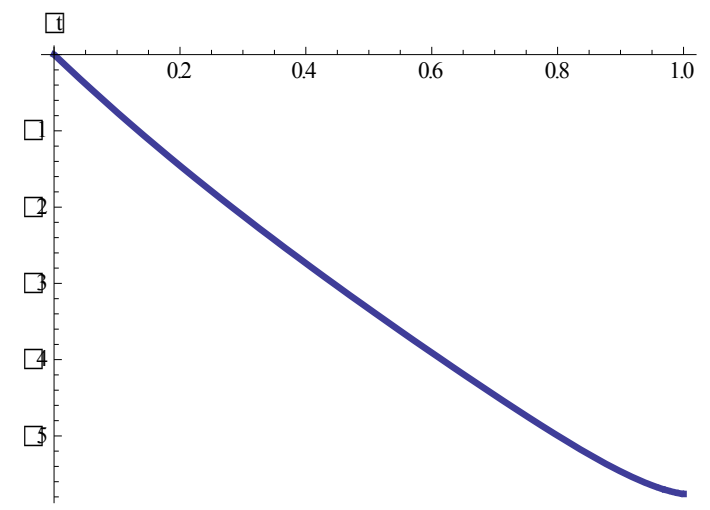

$\Delta t=t^{R}-t^{N}<0$

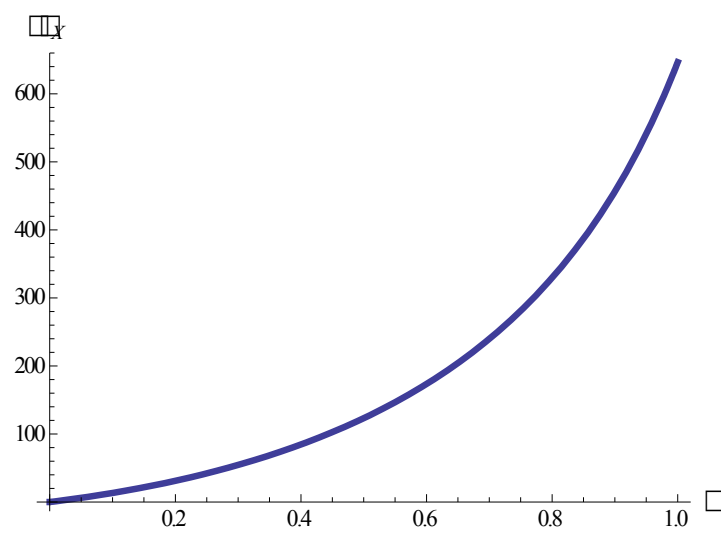

$\Delta \pi_{X}=\pi_{X}^{R}-\pi_{X}^{N}>0$

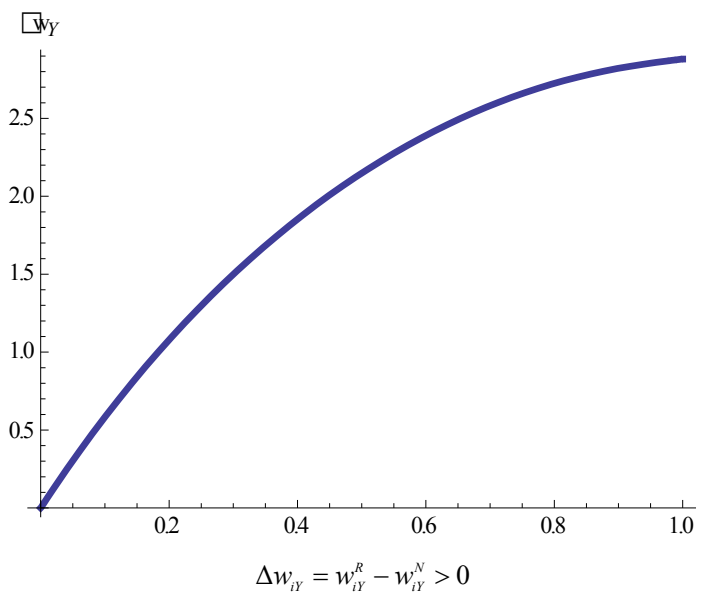

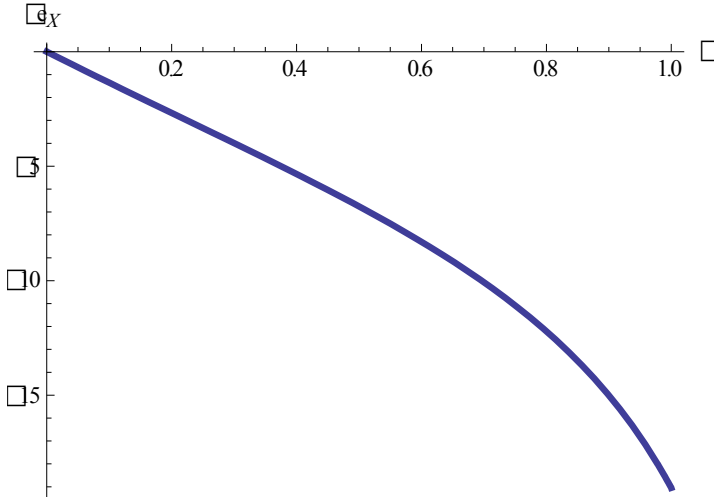

$\Delta e_{X}=e_{X}^{R}-e_{X}^{N}<0$
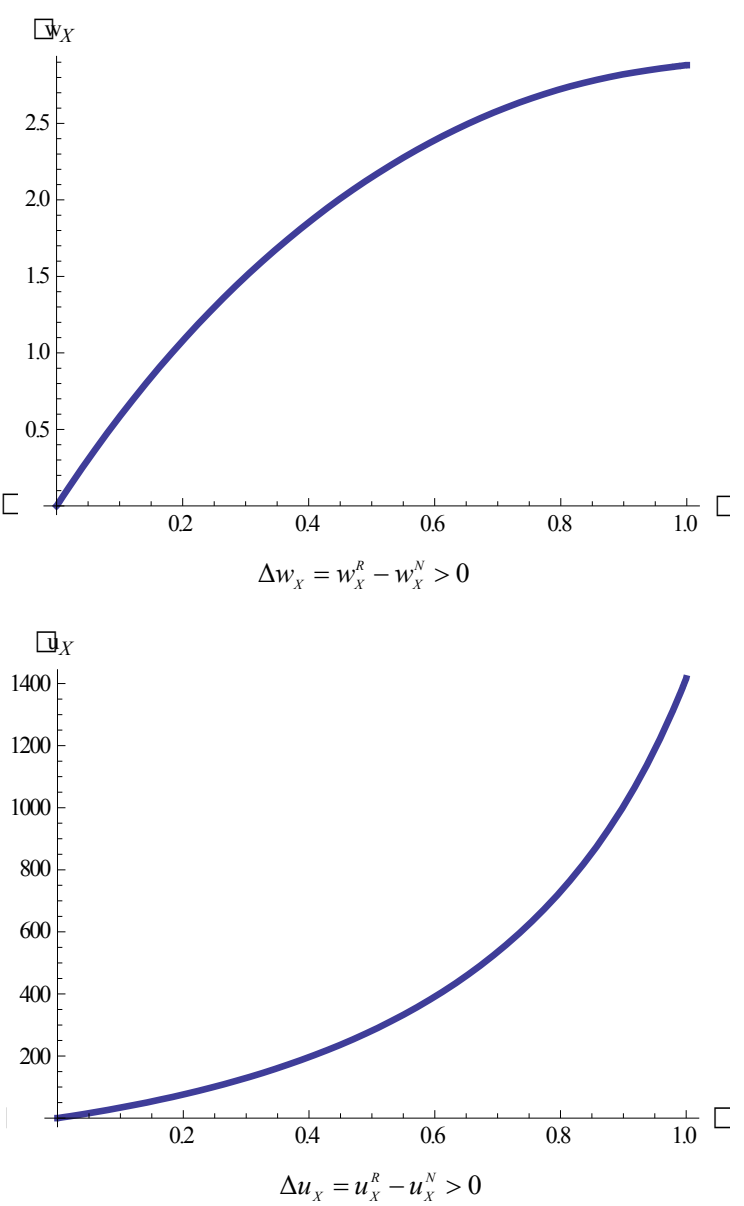


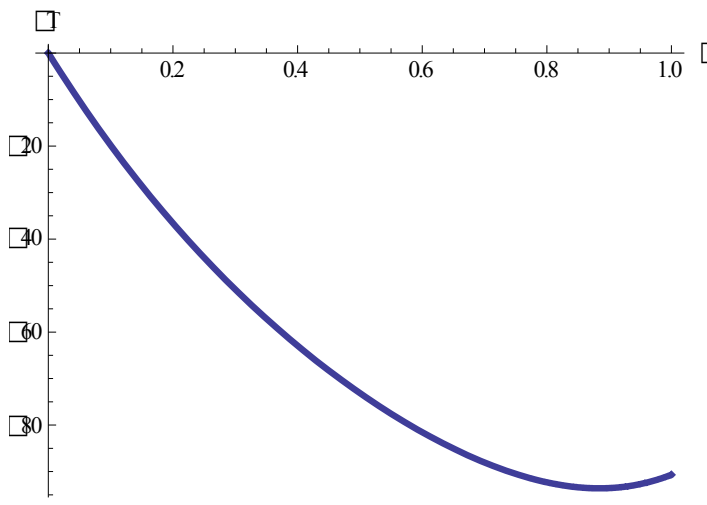

$\Delta T=T^{R}-T^{N}<0$

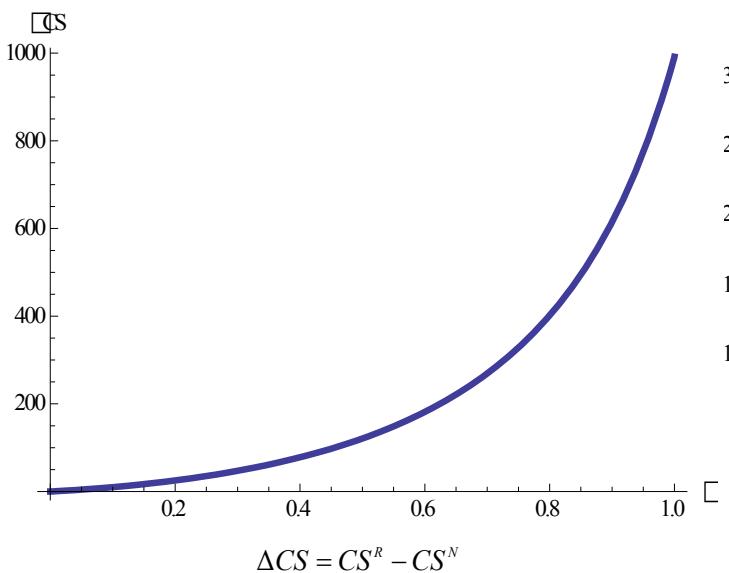

FD

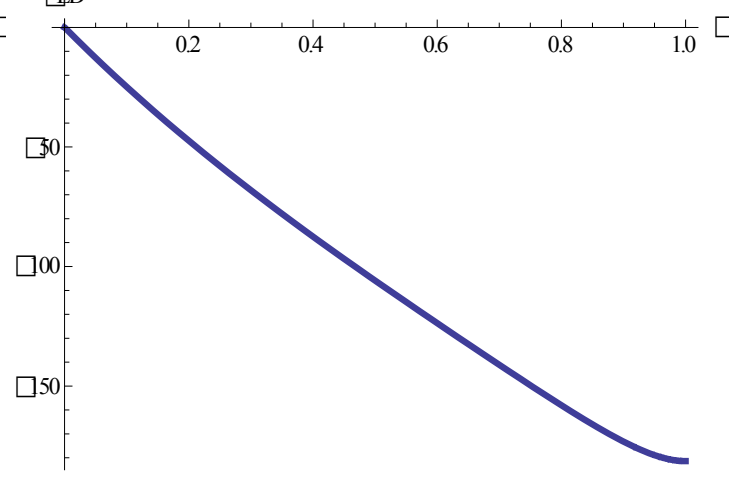

$\Delta E D=E D^{R}-E D^{N}<0$

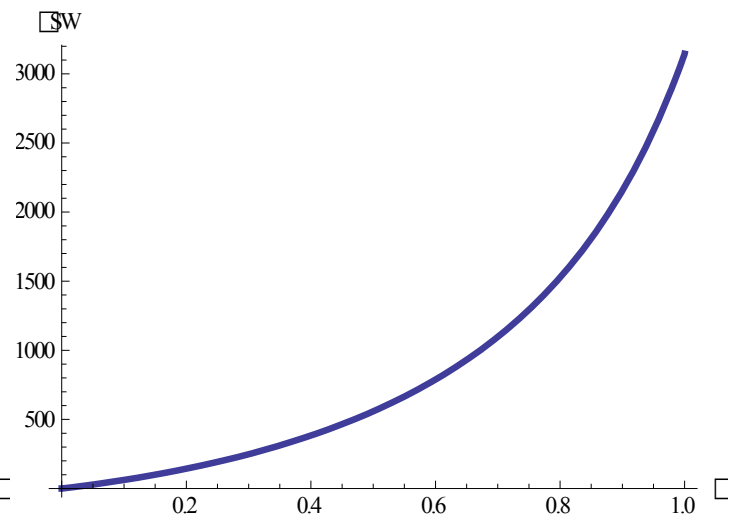

$\Delta S W=S W^{R}-S W^{N}$

Figure A1. Graphical analysis of the numerical simulation. Note: the data source is organized by author.

Through the above graphical analysis, we can clearly understand the comparison of all important parameters and can determine the impact of environmentally oriented CSR.

\section{Appendix B}

We can see that a union's utilities are $u_{X}=\frac{50 A^{2}}{441}$ and $u_{Y}=\frac{A^{2} n}{4+4 n}$, and the utility of united union $U=\frac{A^{2}(200+641 n)}{1764(1+n)}$ is equal to $u_{X}+u_{Y}$ in Lemma 1 .

We can also see that a union's utilities are $u_{X}=\frac{\left(2-\gamma^{2}\right)(2 A(-5+\gamma(2+\gamma))+\gamma(-9+\gamma(2+3 \gamma)))^{2}}{4(3-2 \gamma)^{2}(7+\gamma(1-\gamma(3+\gamma)))^{2}}$ and $u_{Y}=\frac{A^{2} n}{4(1+n)}$, and the utility of united union $U=\frac{\left(2-\gamma^{2}\right)(2 A(-5+\gamma(2+\gamma))+\gamma(-9+\gamma(2+3 \gamma)))^{2}}{4(3-2 \gamma)^{2}(7+\gamma(1-\gamma(3+\gamma)))^{2}}+\frac{A^{2} n}{4(1+n)}$ is equal to $u_{X}+u_{Y}$ in Lemma 2. The other results are also identical to those of Lemma 1 and Lemma 2 under the united union structure in Section 7. 